\title{
Sheltering Aboriginal Women with Mental Illness in Ontario, Canada: Being "Kicked" and Nurtured
}

Phyllis Montgomery ${ }^{1 *}$, Sarah Benbow ${ }^{2}$, Laura Hall ${ }^{3}$, Denise Newton-Mathur ${ }^{1}$, Cheryl Forchuk ${ }^{4}$ and Sharolyn Mossey ${ }^{1}$

${ }^{1}$ School of Nursing, Ramsey Lake Road, Laurentian University, Sudbury, Ontario, Canada

${ }^{2}$ Faculty of Health Sciences, Arthur Labatt Family School of Nursing, Western University, London, Ontario, Canada

${ }^{3}$ York University, 4700 Keele St., Toronto, Ontario, Canada

${ }^{4}$ Arthur Labatt Family School of Nursing, Lawson Health Research Institute, 1151, Richmond Street, Western University, London, Ontario, Canada

*Corresponding author : Phyllis Montgomery, Professor, School of Nursing, Ramsey Lake Road, Laurentian University, Sudbury, Ontario, Canada, Tel: (705) 675-1151 Ext. 3818; E-mail: pmontgomery@laurentian.ca

Received date: April 08, 2014, Accepted date: May 05, 2014, Published date: May 08, 2014

Copyright: ( $) 2014$ Montgomery P, et al. This is an open-access article distributed under the terms of the Creative Commons Attribution License, which permits unrestricted use, distribution, and reproduction in any medium, provided the original author and source are credited.

\begin{abstract}
Objective: For individuals living with mental health challenges, the provision of homeless shelters can offer a temporary respite in overwhelming life circumstances. There is, however, limited evidence regarding the subjective experiences associated with shelter services by Aboriginal women in Canada. The purpose of this study was to develop an understanding of the day-to-day experiences of Aboriginal women as they seek and provide safety, comfort, health, and healing in the context of mental illness and insecure housing.
\end{abstract}

Methods: The study design was a secondary qualitative analysis of data collected in a primary mixed method study involving persons faced with mental health and housing challenges in southern Ontario, Canada. Narrative analysis was used to identify common experiences among 11 shelter service users and 10 shelter service providers, all of whom where Aboriginal women.

Results: Regardless of whether the women received or provided shelter services, they consistently described experiences about being "kicked" and nurtured. Their stories about being "kicked" described experiences associated with compounding losses. Juxtaposed to this reality, were accounts about being nurtured or "lifting each other up." Nurturing relations were essential to address the pervasive health and social disparities experienced by the women. Relationships within homeless shelters were directed towards supporting the health and well-being of individual women and their broader community.

Conclusion: This study's findings extend the community mental health body of nursing literature regarding Aboriginal women living with mental illness and homelessness. Despite the protective and restorative components of nurturing within shelter services, cooperative networks need to be developed to build communities that eradicate the pervasive losses experienced by Aboriginal women who continue to be "kicked."

Keywords: Aboriginal women; Mental health; Homelessness; Shelters; Qualitative

\section{Introduction}

In Canada, the health and well-being of Aboriginal women is particularly compromised in comparison to their non-Aboriginal female counterparts. The individual and collective vulnerabilities of Aboriginal women are represented by multiple intersecting "realities of everyday life in which Aboriginality, female gender, racism, sexism and poverty are lived and experienced simultaneously, not sequentially" [1]. It has been well documented that Canadian Aboriginal women have a significantly lower life expectancy [2] and higher prevalence of depression, addictions, and self-injury $[3,4]$. Further, Aboriginal women are reported to have higher social surveillance, incarceration rates, incidences of violence, transgenerational trauma, discrimination and lower income levels; all of which impact health [4-8]. As a group, Aboriginal women are more often homeless compared to both non-Aboriginal women and
Aboriginal men [9], which has further compromised their overall wellbeing inclusive of mental health.

Impacted by entrenched historical and contemporary health and social inequities $[6,10]$ Aboriginal women often enter homeless shelter services to seek refuge $[11,12]$. For insecurely housed Canadians, such as Aboriginal women, the use of adult shelter services has been fundamental to sustaining day-to-day survival in the midst of entrenched health and social disparities. In this way, homeless services focus predominantly on fulfilling immediate basic needs $[13,14]$. Shelters offer services that are intended to transition vulnerable women from homelessness to stable housing through the concurrent provision of necessary health and social services. The coordination and timeliness of appropriate services to break the cyclic nature of homelessness is challenging given the variability and complexity of needs that threaten well-being $[11,15]$.

In general, Canadian women have described their homeless shelter experiences as disempowering, un-dignifying and regimented $[7,16]$. Liebow's ethnographic study [17] suggested that racial divisiveness is a pervasive within shelter life. In particular for women with mental 
illness who may be subjected to overt and covert hostility associated with racial tensions, self-imposed isolation was a protective strategy that further undermines their mental health [17]. Other authors reported that the need to balance individual and collective security is a complex undertaking for community workers navigating cultural tensions and advocating for broader social justice [14,18,19]. Further, social disparities impede exit from the shelter circuit keeping Aboriginal women dependent on services which may not be culturally sensitive [20].

Several authors have identified the need for focused research that explores the well-being of Aboriginal women when their capacity to fulfil family and community responsibilities is disrupted $[8,14,21]$. The purpose of this study therefore, was to develop an understanding of the day-to-day experiences of Aboriginal women as they seek safety, comfort, health, and healing in the context of mental illness and insecure housing. More specifically, this study revealed the accounts of receiving and providing shelter services as told by Aboriginal women. Green [10] identified that individual and collective experiences of Aboriginal women are reflective of social realities that warrant acknowledgement and intervention by psychiatric mental health nurses. The results of this study have the potential to sensitize psychiatric mental health nurses to the complexity of Aboriginal women's quest to achieve wellness of body, mind and spirit as described by the First Nations and Inuit Mental Wellness Advisory Committee [22], an underdeveloped area of psychiatric mental health nursing research.

\section{Methods}

\section{Design}

This study's design was a supplementary secondary qualitative approach to examine a data subset not fully addressed in a primary study [23]. The five-year primary study used a mixed methods participatory action approach to examine housing issues and solutions for individuals with mental illness [24]. It generated an extensive repository of data, approved for secondary analyses. The dataset, particular to Aboriginal women who used or provided shelter services, was accessed for this supplementary study to elicit a focused description of their knowledge about and experiences of shelter care. This secondary analysis was important to search for new knowledge that is informed by the voices of Aboriginal women [12,25,26].

Access to the ethically approved dataset and its security was maintained by an author who was also the academic lead of the original study. To uphold the ethical principle of beneficence, the anonymity and uniqueness of each woman was safeguarded through data extraction, secure storage, and representation in the findings. This was particularly salient given that participant data could reveal their identity to members of their small communities. Cultural sensitivity throughout the research process was guided by the Aboriginal research team members.

\section{Sample and sample}

The original study recruited individuals from a variety of mental health, housing and social services in southern Ontario all of who were involved in either service use or service provision [24]. For this study, data was extracted from group interviews specific to 21 Englishspeaking women who self-identified as Aboriginal, including First Nation, Métis, or Inuit. It is acknowledged that each of these three groups of Aboriginal peoples is a distinct nation with unique heritages, languages, cultural practices, and spiritual beliefs as described by the Government of Canada [27]. Of this sample, 11 self-identified as having a history of mental illness and insecure housing that required use of homeless shelter services. The remaining 10 Aboriginal women in the dataset were employed in the provision of homeless shelter services.

\section{Data collection and analysis}

Data particular to the 21 Aboriginal women were extracted from the eight primary study tape-recorded verbatim focus group transcripts, which were anonymized. Evident across the transcripts were stories co-constructed during participation in the focus groups. Stories, the unit of analysis in this study, are told to communicate internal understanding of life experiences and situations [28,29].

Data analysis involved a structural narrative approach to systematically identify and group stories based on shared structure, meaning, and function [30]. The structure refers to how stories are constructed by participants [31]. The story meaning represents the participants' intended message [32]. Finally, the function of a story denotes the implications of what is being told to the researcher [30]. This approach necessitated the research team members to engage in serial open conversations leading to shared interpretations of the structure, meaning and function of each story grouping with the intent of honouring the voices of the participants. This interactive and iterative approach was supported by the work of Peat [33].

To preserve each Aboriginal woman's anonymity, entire stories are not presented. Rather, one or two sentences were extracted from the accounts of several women to illustrate story structure, meaning, and function while indicating auditability, analytic logic and credibility [29]. Within these extractions textual clarifications were added within square brackets. The use of quotations was to note the precise lexicon of participants not attributable to or tidied by the researchers.

\section{Results}

The women told 124 stories, describing daily experiences involving tenacious efforts to secure a "good life" for themselves and others in the context of mental illness and insecure housing. The experiences described by shelter service users and providers were similar. Their stories, reflecting a cohesive account of sheltering while vulnerable, were labelled being "kicked" and being nurtured. To varying degrees, these two groups of contrasting stories occurred in the lives of all participants. Below is a sequential presentation of the structure, meaning, and function of each of the two story groups.

\section{Being "Kicked" Stories}

Within this first group of stories, service users and providers described a legacy of historical oppression with which they live on a day-to-day basis. Largely influenced by negativity, the women shared experiences likened to being perpetually "kicked," and thus the labelling of this group of stories. For some service users, being "kicked" was attributed to not only having a mental illness and insecure housing but also the "colour of my skin." For some service users, being "kicked" was related to generalization of Aboriginal women as "untrustworthy." 


\section{Structure}

The common structural element across all of the "kicked" stories was that of multiple, diverse, compounding and often unresolved loss. Service users and providers detailed removal from or denial of resources such as personal possessions, relationships, autonomy, community influence, service and land often entrenched in racial discrimination. The following excerpts illustrate the element of loss within the "kicked" stories.

Service user 3: My grandfather makes [a special artefact] and he is 87 years old. He gaveme one. I had it in the apartment. I lost the apartment and I lost my treasure. He [landlord] threw everything in the dump.

Service user 5: I'm in a shelter because I lost my boyfriend and I lost our place.

Service user 9: We are actually told we [Aboriginal women] are no good for nothing and there is no way around that.

\section{Service provider 2: And out here all we have is our skin.}

Service provider 5: Our women have no property rights. When we leave [our reserve] we leave our land our home what we have built our whole life. As an Aboriginal woman I understand our reality, our issues, the Indian Act.

Service provider 6: We know what it is like to deal with people who don't care. We know what it is like to be assumed that you are guilty even before you have a chance to explain. We know what that feeling is as it is also our experience. It is also our sisters' and brothers' experience. It happened to our parents, our cousins, our boyfriends, our girlfriends. It is there and it is bad.

The presence of repeated losses, reinforced women's perception of exclusion, objectification and deprivation, which was characteristic of the experience of being "kicked." Service users who were "kicked" out of places and service providers, who were excluded or "kicked" out of processes, witnessed the accumulation of their losses. Ultimately, this created an entrenchment of their respective needs as "virtually invisible" and unmet. Being kicked distanced them from where "they want [ed] to be and how they need[ed] to be." From a service user perspective, "always having doors slammed in your face" further threatened mental well-being. Service providers recognized that in the presence of loss and absence of stable mental health and secure housing, shelters users would remain "broken," "out of place" and preoccupied with just trying to "survive day-to-day."

\section{Meaning and function}

The women told "kicked" stories to convey cumulative losses of that which was perceived as essential to health and well-being. Persistent discrimination and social inequities became commonplace in the lives of shelter service users and providers. Both shelter users and providers gave testimony to the contextual aggression and deprivation within their life- and work-circumstances. The participants acknowledged that an "unsupportive society" heightened suffering and perpetuated their sense of loss. With each repetitive and forceful kick, both shelter users and providers came to live in a sustained state of vulnerability. As described by a service provider, "their [shelter users'] crust starts to form," and "then their mental illness really kicks in." Succinctly stated by one shelter user, her life in disadvantage was "a constant audition" for a more meaningful and healthy existence. Overall, being kicked restricted women's capacities and opportunities for "peace."
These stories function to provide insight into the insidious nature of loss that pervades the life experiences of both shelter service users and providers in this study. Although experienced to varying degrees, each woman was affected, directly or vicariously, by society's ineffectual response to eradicate homelessness and promote mental well-being. Further, this group of stories identifies the need for mental health nurses, as members of the broader community mental health network, to provide culturally appropriate individualized assessments and cooperative interventions relative to trauma that could be experienced by some Aboriginal women using and providing homeless shelter services. A failure to consider the possibility of such trauma risks "further and further and further and further and further" omissions in the comprehensive and coordinated service provision for Aboriginal women living with mental illness and insecure housing.

\section{Being Nurtured Stories}

Within the second group of stories, service users and providers both described the need for and practices of gently "lifting each other up" in the context of the life circumstances described in the being "kicked" stories. Most nurturing stories described providers' attempts to "contribute good things" through nurturing of self, "our sisters," and "our people as a whole." Nurturing involved a respectful attention to the physical, emotional, social, spiritual, and cultural aspects of one another.

\section{Structure}

The common structural element across the being nurtured stories was partnering to address diverse needs. The presence of unmet needs necessitated respectful connections between service users, providers and external others to fulfil immediate needs. The following excerpts illustrate the impetus for partnering within one another within the nurturing stories.

Service user 2 : When I say I am sick, I am really sick. And just like other people I need help from those [individuals who are supposed to help].

Service user 6: As a single mother with kids I feel I need to hook up with someone because I can't do this alone to make ends meet. I would love to be on my own but I can't right now.

Service user 7: At many shelters, there are certain times where we can't eat. We don't even have a place to sit at [name of a particular shelter]. At this shelter they do have good meals and fresh beds. If I don't have a place to sit I now know I can come here.

Service provider 8: We had a woman who was going to be evicted while she was in the hospital. She called us. We went to her house and packed her stuff up for her. Whatever we can do to help we try to do it.

Service provider 10: We care for some women who are so poor that they can't help their children. Not that they don't want to, not that they are bad people, not that they are not worthy. They simply can't do it alone

Service provider 5: The Indian Act has to be interpreted. It is huge for our people in terms of where we can live, what are our rights, all those things that significantly impact on Aboriginal women.

Nurturing involved "providing for" and "being available to" one another, "one woman at a time." The acts were to foster in the service users a sense of being "cared for" and feeling "cared about." Efforts to counter the described losses in the "kicked" stories and establish a 
support network required service providers to be "pretty sophisticated in social politics." Their nurturing practices were guided by reasonable actions that addressed a woman's needs rather than rigid compliance with "institutionalized routines." For example, providers recognized the need to "let some women sleep" and "take the time they needed" to initiate restoration of "body, mind and spirit." Cultural sensitivity was described as a welcome component of nurturing interactions. Simple actions such as speaking "our own languages" and sharing foods that "not only sustained us physically, but provided cultural nourishment" was described as means of connecting with and nurturing one another.

\section{Meaning and function}

Participants told being nurtured stories to illustrate the potential of positive and authentic connectedness in overcoming unmet needs both to promote individual "balance" and a create a community of healthy Aboriginal women. This group of stories portray optimism for a future in which Aboriginal women's identity as "beautiful, strong, caring and kind" women is unmasked. These stories function to demonstrate that authentic nurturing focused on the individualized fulfilment of needs has the potential to extend "servicing" to "healing" for Aboriginal women. Nurturing and healing work that is initiated by service users and providers within homeless shelters, complements community mental health nurses' overall efforts for optimized wellbeing.

\section{Discussion}

This study's findings extend the community mental health body of nursing literature regarding Aboriginal women living with mental illness and homelessness. In juxtaposition to being "kicked", being nurtured stories present a simultaneous reality characterized by genuine concern and person-centred actions between and among Aboriginal women. In concert, the two types of stories illustrate the importance of validating the historical and contemporary contextual reality of Aboriginal women and their strategic efforts to actualize person dignity and connectedness with valued others. The being "kicked" and nurtured stories depict individual and shared efforts towards balance of body, mind, and spirit. Although the mandate of homeless shelter services is not mental health, the women's stories demonstrate that nurturing has the potential to promote individual mental well-being. Within spaces that offer safety and comfort, even if time-limited, a woman's journey for physical, emotional, mental, cultural and spiritual well-being is made possible [8]. As such, individuals who receive and provide sheltering services and the organizations in which services are structured are integral to building a community that not only espouses but enacts social justice.

Community building, as conceptualized by Walter and Hyde [34] necessitates authentic "communityness," beyond the sharing of geographic space, members are connected by activities that foster a sense of belonging through the fair and equitable distribution of community resources. The nurtured stories within this study suggest the presence of emergent communityness. In contrast, "kicked" stories emphasize the ongoing presence of health and social inequities that continue to pervade the lives of Aboriginal women, hallmarks that communityness and social justice have not yet been achieved. Community building practices involve multidimensional engagements using a range of strategies to acknowledge diverse beliefs, interests, and strengths, with the goal of building "capacity of the entire system, and all its participants, to operate as community" [34].
Mental health nurses, as established members of community are well positioned to acknowledge the strengths of those with whom they interface, inclusive of shelter users, shelter workers and organizations. Exploring ways of working together for community building necessitates affirming and acknowledging one another's legitimacy and legal entitlements, embracing diversity, identifying common goals such as health equity, engaging in creative planning, integrating multiple visions and strategies, and accepting responsibility to remain connected [34]. Shelter service user and provider partnering for fulfilment of immediate needs as represented in the nurturing stories in this study can be supported by mental health nurses' conscious, inclusionary, and community building practices for individual and population health $[10,34,35]$. This study's results suggest an orientation for fostering community development as opposed to a singular best practice to address the disparaging circumstances of individual women involved in shelter life. As argued by Johnstone [36], mental health nurses have a responsibility to challenge the status quo and advocate for inclusivity as strategies to subvert the normalized culture of prejudice and discrimination against vulnerable populations.

The Canadian Federation of Mental Health Nurses [37] asserts that mental health nurses must consider the impact of culture, class, ethnicity, language, stigma, and social exclusion on health and health promotion. For nurses working with Aboriginal women living with mental illness and insecure housing, this is particularly relevant given historical and contemporary losses. The loss feature of the being "kicked' stories can be perceived as a manifestation of poverty and exclusion associated with colonialism $[8,26]$. According to de Leeuw, Greenwood and Cameron [38], the Canadian legacy of colonialization permeates the mental health of Aboriginal peoples. Thus, nurses' mindfulness of the impact of historical processes, such as the Indian Act, and social determinants, provides a more comprehensive assessment of Aboriginal women's mental health [8,13,39]. Koptie [40] cautioned that definitions of poverty, underpinned by tenets of assimilation, negate the efforts of Aboriginal people to overcome their 'trajectory of suffering' in a colonial context.

The being nurtured stories not only pay tribute to the resilience and strength of Aboriginal women in adversity, but support the movement away from an account solely focused on abuse and pain to one of strength, hope and acknowledgment of Aboriginal experiential knowledge $[41,42]$. Aboriginal worldviews generally tend to emphasize responsibility for the whole of the community rather than just for individual members. Nurses' awareness of this orientation may foster a partnering with Aboriginal women in their efforts to shift practices from an emphasis on service provision to connectedness and inclusivity with sensitivity to context and culture. This 'coming-toknow' [33] requires attention to processes through further dialogue among a range of community stakeholders to understand the circumstances required for Aboriginal women to actively engage in their wellness [25]. Forging authentic relations between mental health and social service providers is imperative to ensure that individual rights and needs are met, and at a much broader level social inclusion and social action for community building can be achieved for marginalized populations $[14,43,44]$. To bridge the chasms that continue to exist within health and social services, mental health nurses can function in a variety of roles such as care advocate, case manager, and consultant. The roles of care manager [45] and navigator [46] to support individuals living with other chronic challenges warrant examination for feasibility with this study's population. 
In conclusion, future research guided by Aboriginal methodologies, such as sharing circles [47], is recommended to extend the findings of this study. Such approaches offer the possibility of acquiring further understanding of the complex realities of mental health and housing challenges for Aboriginal women in a culturally appropriate manner beyond what was accomplished in this study. This study did reveal the juxtaposed realities experiences by Aboriginal women in homeless shelters. Despite the protective and restorative components of nurturing within shelter services, cooperative networks need to be developed to build community that eradicates the pervasive losses and mental distress experienced by Aboriginal women.

\section{References}

1. Culhane D (2009) Narratives of hope and despair in Downtown Eastside Vancouver. In Kirmayer LJ, Valaskakis GG, In Healing Traditions: The Mental Health of Aboriginal Peoples in Canada. 160-177. University of British Columbia Press, Vancouver BC.

2. Smylie J (2009) The health of aboriginal peoples. In Raphael D, Social determinants of health: Canadian perspectives (2nd edn p. 280-301). Canadian Scholars Press, Toronto, ON.

3. Donner L, Isfeld H, Haworth-Brockman M, Forsey C (2008) A profile of women's health in Manitoba. Prairie Women's Health Centre of Excellence, Manitoba, Winnipeg.

4. Reading CL, Wein F (2009) Health inequalities and social determinants of Aboriginal Peoples' health. National Collaborating Centre for Aboriginal Health, Prince George, British Columbia.

5. Haskell L, Randall M (2009) Disrupted attachments: A social context complex trauma framework and the lives of aboriginal peoples in Canada. Journal of Aboriginal Health 5: 48-99.

6. Native Women's Association of Canada (2004). Aboriginal women and housing: For the Canada-Aboriginal Peoples roundtable sectoral followup session on housing. Native Women's Association of Canada, Ottawa, Ontario.

7. Scott S (2007) All our sisters: Stories of homeless women in Canada. Broadview Press, Peterborough, Ontario.

8. Stout R (2010) Urban Aboriginal women and mental health (Project \#215). Prairie Women's Health Centre of Excellence, Winnipeg, Manitoba.

9. Native Women's Association of Canada (2007) Aboriginal women and homelessness: An issue paper. Author, Corner Brook, Newfoundland.

10. Green BL (2010) Applying interdisciplinary theory in the care of Aboriginal women's mental health. J Psychiatr Ment Health Nurs 17: 797-803.

11. Richter MS, Chaw-Kant J (2008) A case study: Retrospective analysis of homeless women in a Canadian city. Women's Health \& Urban Life 7: 7-19.

12. Ruttan L, LaBoucane-Benson P, Munro B (2008) "A story I never heard before": Aboriginal young women, homelessness, and restoring connections. Pimatziwin: A Journal of Aboriginal and Indigenous Community Health 6: 31-54.

13. Benbow S, Forchuk C, Ray SL (2011) Mothers with mental illness experiencing homelessness: a critical analysis. J Psychiatr Ment Health Nurs 18: 687-695.

14. Berman H, Mulcahy GA, Forchuk C, Edmunds KA, Haldenby A, et al. (2009) Uprooted and displaced: a critical narrative study of homeless, Aboriginal, and newcomer girls in Canada. Issues Ment Health Nurs 30: 418-430.

15. Young MG, Moses JM (2013) Noeliberalism and homelessness in the western Canadian arctic. Canadian Journal of Nonprofit and Social Economy Research 4: 7-22.

16. Novac S (1996) A place to call one's own: New voices of dislocation and dispossession. Status of Women Canada, Ottawa, Ontario.
17. Liebow E (1993) Tell them who I am: The lives of homeless women. Penguin Books, New York, New York.

18. Krausz RM, Clarkson AF, Strehlau V, Torchalla I, Li K, et al. (2013) Mental disorder, service use, and barriers to care among 500 homeless people in 3 different urban settings. Soc Psychiatry Psychiatr Epidemiol 48: $1235-1243$.

19. Lyon-Callo V (2004) Inequality, poverty, and neoliberal governance: Activist ethnography in the homeless sheltering industry. Broadview Press, Peterborough, Ontario.

20. Thurston WE, Oelke ND, Turner D, Bird C (2011) Final report: Improving housing outcomes for Aboriginal people in Western Canada: National, regional, community and individual perspectives on changing the future of homelessness. Department of Community Health Services, University of Calgary, Alberta.

21. Ruttan L, LaBoucane-Benson P, Munro B (2010) "Home and Native Land": Aboriginal young women and homelessness in the city. First Peoples Child \& Family Review 5: 67-77.

22. First Nations and Inuit Mental Wellness Advisory Committee (2007) Draft Strategic Action Plan for First Nations and Inuit Mental Wellness. Author, Ottawa, Ontario.

23. Heaton J (2008) Secondary analysis of qualitative data. In Alasuutari P, Bickman L, Brannen J (eds.) The SAGE handbook of social research methods (p. 506-519). SAGE Publications, London, England.

24. Forchuk C, Csiernik R, Jensen E (2011) Homelessness, housing and the experiences of mental health consumer-survivors: Finding truths creating change. Canadian Scholars Press, Toronto, Ontario.

25. Kenny C (2006) When the women heal: Aboriginal women speak about policies to improve the quality of life. American Behavioral Scientist: 50: 550-561.

26. Smith LT (1999) Decolonizing Methodologies: Research and Indigenous Peoples. Zed Books, New York, New York.

27. Government of Canada (2012) Aboriginal Affairs and Northern Development Canada: Terminology.

28. Holloway I, Freshwater D (2007) Narrative research in nursing. Blackwell Publishing, Oxford, England.

29. Riessman CK (2008) Narrative methods for the human sciences. SAGE Publishers, Los Angeles, California.

30. Bailey PH, Montgomery P, Mossey S (2013) Narrative Inquiry. In Beck CT (ed.) Routledge international handbook of qualitative nursing research (p.268-281). Routledge, Abingdon, Oxon.

31. Labov W, Waletzky J (1972) Narrative analysis: Oral versions of personal experience. In Helms J (ed.) Essays on the verbal and visual arts (p. 12-44). University of Washington Press, Washington, Seattle.

32. Agar M, Hobbs JR (1983) Natural plans: Using AI planning in the analysis of ethnographic interviews. Ethos: 11, 33-48.

33. Peat FD (2002) Blackfoot Physics: A journey into the Native American Worldview. Planes Press, Grand Rapids.

34. Walter CL, Hyde CA (2012) Community building practice: An expanded conceptual framework. In Minkler M. (ed.) Community organizing and community building for health and welfare (p. 78-94). Rutgers University Press, New Brunswick.

35. Benbow S (2009) Societal abuse in the lives of individuals with mental illness. Canadian Nurse 105: 30-32.

36. Johnstone MJ (2001) Stigma, social justice and the rights of the mentally ill: challenging the status quo. Aust N Z J Ment Health Nurs 10: 200-209.

37. Canadian Federation for Mental Health Nurses (2006) Canadian standards for psychiatric-mental health nursing.

38. De Leeuw S, Greenwood M, Cameron E (2009) Deviant constructions: How governments preserve colonial narratives of addictions and poor mental health to intervene into the lives of Indigenous children and families in Canada. International Journal of Mental Health and Addictions 8: 282-295.

39. Browne A, Smye V, Varcoe C (2005) The relevance of postcolonial theoretical perspectives to research in Aboriginal health. Canadian 
Citation: Montgomery P, Benbow S, Hall L, Mathur DN, Forchuk C, et al. (2014) Sheltering Aboriginal Women with Mental Illness in Ontario, Canada: Being "Kicked" and Nurtured . J Nurs Care 3: 164. doi:10.4172/2167-1168.1000164

Page 6 of 6

Journal of Nursing Research 37: 16-37. http://www.ncbi.nlm.nih.gov/ pubmed/16541817.

40. Koptie S (2010) Inferiorizing Indigenous communities and intentional colonial poverty. First Peoples Child and Family Review 5: 96-106.

41. Brascoupé S, Waters C (2009) Exploring the applicability of the concept of cultural safety to Aboriginal health and community wellness. Journal of Aboriginal Health 5: 6-41.

42. McKegney S (2007). "We have been silent too long." In Magic weapons: Aboriginal writers remaking community after Residential School (pp. 59-99). University of Manitoba Press, Winnipeg, Manitoba.

43. Canadian Nurses Association (2010) Social justice: A means to an end, an end in itself.

44. Labonte R (2012) Community, community development, and the forming of authentic partnerships: Some critical reflections. In Minkler
$\mathrm{M}$ (ed.) Community organizing and community building for health and welfare (p. 95-109). Rutgers University Press, New Brunswick.

45. Ciccone MM, Aquilino A, Cortese F, Scicchitano P, Sassara M, et al. (2010) Feasibility and effectiveness of a disease and care management model in the primary health care system for patients with heart failure and diabetes (Project Leonardo). Vasc Health Risk Manag 6: 297-305.

46. Wells KJ, Battaglia TA, Dudley DJ, Garcia R, Greene A, et al. (2008) Patient navigation: state of the art or is it science? Cancer 113: 1999-2010.

47. Lavalle LF (2009) Practical application of an Indigenous research framework and two qualitative indigenous research methods: Sharing circles and Anishnaabe symbol-based reflection. International Institute for Qualitative Methodology 8: 21-40 